\title{
Evaluation of propidium monoazide-based qPCR to detect viable oocysts of Toxoplasma gondii
}

\author{
Angélique Rousseau ${ }^{1,2,3} \cdot$ Isabelle Villena ${ }^{2} \cdot$ Aurélien Dumètre $^{4} \cdot$ Sandie Escotte-Binet $^{2} \cdot$ Loïc Favennec $^{3}$. \\ Jitender P. Dubey ${ }^{5} \cdot$ Dominique Aubert $^{2} \cdot$ Stéphanie La Carbona ${ }^{1}$ (D)
}

Received: 21 September 2018 / Accepted: 17 January 2019 / Published online: 7 February 2019

(C) The Author(s) 2019

\begin{abstract}
Information on the viability of Toxoplasma gondii oocysts is crucial to establish the public health significance of this environmental transmission stage that can contaminate water and foods. Interest for molecular-based methods to assess viability is growing and the aim of our study was to assess, for the first time, a propidium monoazide (PMA)-qPCR approach to determine the viability of $T$. gondii oocysts. Untreated and heat-killed $\left(99^{\circ} \mathrm{C}, 5 \mathrm{~min}\right)$ oocysts were incubated with PMA, a photoreactive DNA binding dye, and analyzed by confocal microscopy and flow cytometry to characterize oocysts' dye permeability. Different PMA concentrations (50 to $150 \mu \mathrm{M}$ ), incubation temperatures $\left(22,37\right.$, and $\left.45^{\circ} \mathrm{C}\right)$, amplicon length, selected targeted gene, and dyes (PMA, PMAxx ${ }^{\mathrm{TM}}$ ) were evaluated to define optimal conditions to discriminate specifically viable oocysts by PMA-qPCR. In theory, PMA binding to DNA would inhibit PCR amplification in dead but not in viable oocysts. Incubation at $22{ }^{\circ} \mathrm{C}$ with $100 \mu \mathrm{M}$ PMA coupled to qPCR targeting a 123-bp sequence of the 529-bp repeat element allowed the distinction between viable and heated oocysts. However, the reduction of viability following heating of oocysts at high temperature was slight and, contrarily to reverse transcriptase-qPCR, the qPCR signal was not totally suppressed in heated suspensions. Therefore, PMAqPCR is able to assess the impact of heating on T. gondii oocysts' viability but underestimates the efficacy of this treatment. The relevance of this technique to evaluate the efficacy of other inactivation processes and assess exposure of humans to this pathogen requires further investigations.
\end{abstract}

Keywords Toxoplasma gondii $\cdot$ Oocysts $\cdot$ Viability $\cdot \mathrm{PMA} / \mathrm{PMAxx}{ }^{\mathrm{TM}} \cdot \mathrm{qPCR} \cdot$ Heat inactivation

Section Editor: Berit Bangoura

Electronic supplementary material The online version of this article (https://doi.org/10.1007/s00436-019-06220-1) contains supplementary material, which is available to authorized users.

Stéphanie La Carbona

s.lacarbona@actalia.eu

1 ACTALIA, Food Safety Department, 310 Rue Popielujko, 50000 Saint-Lô, France

2 EA 7510, ESCAPE, UFR Médecine, Université de Reims Champagne Ardenne, 51 Rue Cognacq Jay, 51096 Reims, France

3 EA 7510, ESCAPE, UFR Médecine et Pharmacie, Université de Rouen, 22 Bd Gambetta, 76183 Rouen Cedex, France

4 UMR IRD 257 VITROME, IHU-Méditerranée Infection, Aix Marseille University, 19-21 Bd Jean Moulin, 13005 Marseille, France

5 Agricultural Research Service, Beltsville Agricultural Research Center, Animal Parasitic Diseases Laboratory, United States Department Agriculture, Building 1001, Beltsville, MD 20705 2350, USA

\section{Introduction}

Toxoplasma gondii is a protozoan parasite that can infect humans either following ingesting meat containing cysts of the parasite or water and foods contaminated by oocysts. Irrespective of the transmission route, $T$. gondii infections are usually asymptomatic in immunocompetent individuals, resulting in the formation of latent cysts in tissues and organs throughout the body (Robert-Gangneux and Dardé 2012). The parasite can sometimes lead to severe ocular, cerebral, or multivisceral complications, especially in congenitally infected infants and in immunocompromised individuals. T. gondii oocysts were responsible for $2 \%$ of parasitic protozoan waterborne outbreaks reported between January 2004 and December 2010 (Baldursson and Karanis 2011). For the foodborne route, fruits and vegetables consumed raw, unwashed, or minimally processed are of greatest relevance (Kapperud et al. 1996; Baril et al. 1999) and contaminated irrigation waters represent the main vector of contamination 
(Moreno et al. 2018). Shellfishes are also at risk due to their production in potentially contaminated waters (Tei et al. 2016; Ghozzi et al. 2017).

Contrarily to other waterborne pathogenic protozoa such as Cryptosporidium spp. oocysts or Giardia duodenalis cysts, there are no standardized methods available for detection of T. gondii oocysts in water and food samples. Current methods are mainly based on PCR (Villena et al. 2004; Karanis et al. 2012; Wells et al. 2015; Marchioro et al. 2016; Cong et al. 2017; Lalle et al. 2018) and microscopy (Al-Megrin 2010; Harito et al. 2017; Caradonna et al. 2017); however, they do not provide information regarding the viability of the detected parasites. Interest for molecular-based methods to assess viability of food and waterborne parasites is growing. Among them, reverse transcriptase-qPCR (RT-qPCR) can detect mRNA, which is only produced by metabolically active parasites hence considered as viable (Cancino-Faure et al. 2016; Rousseau et al. 2018). However, the main drawback of this method is the persistence of mRNA even in dead organisms (Sung et al. 2005; Xiao et al. 2012; Habtewold et al. 2015). RT-qPCR assays have been developed to detect viable T. gondii oocysts and measure the efficacy of inactivation treatments. However, depending on the treatment applied to oocysts, RT-qPCR assays do not always correlate with infectivity assays (cell culture, mouse inoculation) and consequently can overestimate the number of viable and potentially infective oocysts (Rousseau et al. 2018).

Another promising strategy to assess cell viability relies on the use of nucleic acid intercalating dyes such as ethidium monoazide (EMA) or propidium monoazide (PMA) in combination with specific PCR amplification (Elizaquível et al. 2014; Inoue et al. 2015; Lee et al. 2015; Cattani et al. 2016). This method is based on the membrane integrity of cells, as intact cell membranes (i.e., viable cells) are not permeable to these dyes contrarily to compromised cell membranes (i.e., dead cells). EMA is considered more toxic than PMA and has been shown to enter also in intact cells (Fittipaldi et al. 2012). Hence, PMA should lead to better discrimination of viable cells than EMA, although its mechanism of action remains unclear. Once inside membrane-compromised cells, PMA intercalates into nucleic acids and, after photoactivation, binds covalently to DNA, thanks to its azide group. The insoluble and stable PMA/DNA complex then prevents DNA amplification in dead cells. Consequently, the PCR signal is strongly reduced even suppressed in membrane-compromised cells compared to intact cells. This methodology has been widely applied to detect viable bacteria (Yu et al. 2017), viruses (Fongaro et al. 2016), fungi (Vesper et al. 2008) in food and environmental samples, and Cryptosporidium spp. oocysts and G. duodenalis cysts in water and wastewater effluents (Brescia et al. 2009; Liang and Keeley 2012; AgullóBarceló et al. 2014; Alonso et al. 2014; Ma et al. 2016; Vande Burgt et al. 2018). However, due to incomplete signal suppression, the PMA-PCR-based methods can result in false-positive amplification. Successful PMA-PCR assays depend on a number of factors including the selected targeted gene (length, copy number), PMA incubation and photoactivation conditions, and the presence of organic substances such as clay, silt, or microorganisms (Contreras et al. 2011; Liang and Keeley 2012; Nkuipou-Kenfack et al. 2013). Recent studies have demonstrated that PMAxx ${ }^{\mathrm{TM}}$, a new and improved version of PMA, leads to better discrimination between intact and inactivated Norovirus compared to other intercalating dyes (Randazzo et al. 2016, 2018).

In this study, we developed a PMA-qPCR assay for assessing, for the first time, T. gondii oocysts' viability. Toward that aim, the permeability to PMA of heat-killed versus untreated oocysts was first addressed, and then different experimental conditions were tested to discriminate live/dead oocysts by PMA-qPCR.

\section{Materials and methods}

\section{Parasites}

T. gondii oocysts of VEG genotype III strain were produced and sporulated as previously described (Dubey 2010). Oocyst stock suspension contained $86.1 \%$ of sporulated oocysts and $70 \%$ of viable oocysts as determined by RT-qPCR (see below), and was stored in a $2 \% \mathrm{H}_{2} \mathrm{SO}_{4}$ aqueous solution at $4{ }^{\circ} \mathrm{C}$ until use. Prior to experiments, oocysts were washed three times in sterile distilled water $\left(\mathrm{dH}_{2} \mathrm{O}\right)$ to remove sulfuric acid. Then their concentration was calibrated by counting oocysts in $\mathrm{dH}_{2} \mathrm{O}$ containing $0.5 \%$ sodium dodecyl sulfate (SDS), on Kova Slide (Kova ${ }^{\circledR}$ Slide 10) using a phase contrast microscope (Axioskop 40, Zeiss, magnification $\times 400$ ). Oocysts less than 8 months old were used throughout this study. For comparison between experiments, oocysts of the same age were used. Heat-killed oocysts were obtained following incubation of the parasites in water at $99{ }^{\circ} \mathrm{C}$ for $5 \mathrm{~min}$. The absence of viable oocysts following heating was evaluated with RTqPCR.

\section{PMA/PMAxx ${ }^{\mathrm{TM}}$ treatments}

Untreated or heat-killed oocysts were incubated with 25 to $150 \mu \mathrm{M}$ of PMA (Biotium Inc., Hayward, WI, USA) for $30 \mathrm{~min}$ in dark at room temperature (mean temperature $22{ }^{\circ} \mathrm{C}$ ), $37{ }^{\circ} \mathrm{C}$, or $45{ }^{\circ} \mathrm{C}$, with vortexing every $5 \mathrm{~min}$. PMAxx ${ }^{\mathrm{TM}}$ was applied at $100 \mu \mathrm{M}$ for $30 \mathrm{~min}$ at $22^{\circ} \mathrm{C}$. For each set of qPCR experiments, untreated and heat-killed oocysts were submitted in parallel to the same incubation conditions but in the absence of PMA/PMAxx ${ }^{\mathrm{TM}}$. Then, samples were exposed to a light-emitting diode (LED) source for 15 min using the PhAST Blue photoactivation device $(\lambda=$ 
464-476 nm, 60 W; PhAST Blue PhotoActivation System for Tubes, GenIUL, Barcelona, Spain). After exposure, oocysts were washed three times with $\mathrm{dH}_{2} \mathrm{O}(5000 \times g, 5 \mathrm{~min})$. The supernatant was discarded and the pellet was resuspended in $\mathrm{dH}_{2} \mathrm{O}$.

\section{Confocal microscopy}

Untreated or heat-killed oocysts $\left(10^{6}\right)$ were incubated with $25 \mu \mathrm{M}$ PMA for $30 \mathrm{~min}$ at $22{ }^{\circ} \mathrm{C}$ and processed as described

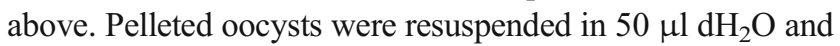
$10 \mu \mathrm{l}$ was used for confocal microscopy analyses. Oocysts' blue autofluorescence and PMA red fluorescence were observed under the appropriate excitation wavelength/filter sets, using a LSM 710 NLO confocal microscope (Zeiss, Germany) linked to a Chameleon infrared biphoton laser (Coherent, USA) and piloted by ZEN software (Zeiss, Germany).

\section{Flow cytometry}

Untreated or heat-killed oocysts $\left(10^{5}\right)$ were stained with $150 \mu \mathrm{M}$ PMA for $30 \mathrm{~min}$ at $22^{\circ} \mathrm{C}$ and processed as described above. Pelleted oocysts were resuspended in $200 \mu \mathrm{ld} \mathrm{d}_{2} \mathrm{O}$. Data acquisition was performed using a BD Accuri ${ }^{\mathrm{TM}} \mathrm{C} 6$ flow cytometer (BD Biosciences, San Jose, USA) equipped with 375 and $488 \mathrm{~nm}$ excitation lasers and set to acquire forward scatter (FSC), side scatter (SSC), and fluorescence. The oocyst autofluorescence and PMA fluorescence were collected on the fluorescence detector at $427 \pm 20 \mathrm{~nm}$ and at $670 \mathrm{~nm} \mathrm{LP}$, respectively. The flow cytometer was set to acquire between 12,000 and 22,000 oocysts in P1 gate. The gate P1 was defined according to the size and granularity of blue autofluorescent elements (i.e., sporulated and unsporulated oocysts). The bivariate dot plot of PMA intensity versus autofluorescence intensity (UV) was established in gate P1 to select the sporulated oocysts and to estimate the percent of sporulated oocysts that have incorporated PMA (PMA+) or not (PMA-). Data were analyzed with the FlowJo LLC software (Oregon, USA).

\section{DNA extraction and qPCR assays}

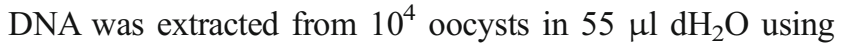
InstaGene ${ }^{\mathrm{TM}}$ Matrix kit as previously described (Hohweyer et al. 2016). DNA was amplified by qPCR targeting the 529bp repeat element (RE; AF487550) or SporoSAG gene (AY492338), producing an amplicon of $81 \mathrm{bp}$ (Toxo-F/ Toxo-R) and $71 \mathrm{bp}$, respectively, as described previously (Palos Ladeiro et al. 2014; Travaillé et al. 2016). For the RE target, two additional forward primers REF2 ( 5 '-TGTG CTTGGAGCCACAGAAG-3') and REF3 (5'-AAGA TGTTTCCGGCTTGGCT-3') were designed using
Primer3Plus according to their melting temperature (around $\left.60{ }^{\circ} \mathrm{C}\right)$, amplicon length $(<300 \mathrm{pb}), \mathrm{GC}$ percent $(50-55 \%)$, presence of $\mathrm{G}$ or $\mathrm{C}$ nucleotides at $3^{\prime} \mathrm{end}$, no repeat sequence, and specificity using Blast score. These two new primers were combined to Toxo- $\mathrm{R}$ reverse primer to increase the amplicon size of the 529-bp RE to $123 \mathrm{bp}$ (R/REF3) and $283 \mathrm{bp}$ (R/REF2). PCR was performed using SimpliAmp ${ }^{\mathrm{TM}}$ Thermal Cycler (ThermoFisher Scientific Inc., Villebon-surYvette, France) in a final volume of $25 \mu \mathrm{l}$ containing $12.5 \mu \mathrm{l}$ of $\mathrm{iQ}^{\mathrm{TM}}$ Supermix (BioRad, Marnes la Coquette, France), $1 \mu \mathrm{l}$ of BSA $(10 \mathrm{mg} / \mathrm{ml}$; SIGMA, France), $1 \mu \mathrm{l}$ of each primer $(20 \mu \mathrm{M}), 0.5 \mu \mathrm{l}$ of probe $(10 \mu \mathrm{M}), 5 \mu \mathrm{l}$ of DNA template, and $4 \mu$ of DNase-RNase-free water (5PRIME). The cycling parameters included a denaturation step at $95{ }^{\circ} \mathrm{C}$ for $3 \mathrm{~min}$ followed by 40 cycles at $95^{\circ} \mathrm{C}$ for $15 \mathrm{~s}$ and $60^{\circ} \mathrm{C}$ for $1 \mathrm{~min}$. Each PCR reaction was performed in duplicate. The Cq value corresponds to the cycle number at which the fluorescence exceeds a fixed threshold and allows the quantification of the amount of the target DNA.

\section{Reverse-transcriptase qPCR assays}

Extraction of mRNA was performed using $10^{4}$ oocysts in $200 \mu \mathrm{ld} \mathrm{d}_{2} \mathrm{O}$ and mRNA was eluted in $50 \mu \mathrm{l}$ of Tris- $\mathrm{HCl}$ $10 \mathrm{mM}$ (Travaillé et al. 2016). Thirty microliters of purified mRNA was then submitted to DNase treatment using $1 \mu \mathrm{l}$ of TURBO $^{\text {TM }}$ DNase (Life Technologies, Villebon-sur-Yvette, France). Following incubation for $30 \mathrm{~min}$ at $37^{\circ} \mathrm{C}$, DNase was inactivated and mRNA was stored at $-20^{\circ} \mathrm{C}$ until analyses. Reverse transcriptase-qPCR assays targeting the SporoSAG gene were performed using the OneStep RT-PCR Kit (Qiagen, Courtaboeuf, France) on $2 \mu \mathrm{l}$ of mRNA as previously described (Travaillé et al. 2016). The cycling parameters included an initial reverse transcriptase step at $50{ }^{\circ} \mathrm{C}$ for $30 \mathrm{~min}$ followed by a denaturation step at $95^{\circ} \mathrm{C}$ for $15 \mathrm{~min}$ and 40 cycles at $95^{\circ} \mathrm{C}$ for $15 \mathrm{~s}$ and $60^{\circ} \mathrm{C}$ for $1 \mathrm{~min}$.

\section{Determination of the percentage of viable oocysts and signal reduction values using PMA or PMAxx ${ }^{\mathrm{TM}}-\mathrm{qPCR}$ assays}

The calculation of viability percentage was based on the theoretical qPCR amplification equation $N_{\mathrm{Cq}}=N_{0} \times 2^{\mathrm{Cq}}$, with $N_{0}$ representing the initial number of oocysts in the PCR mix, $N_{\mathrm{Cq}}$ the number of oocysts in the mix at the $\mathrm{Cq}$ cycle, and 2 represents the optimal qPCR efficiency. The initial number of viable oocysts was derived from the $\mathrm{Cq}$ values obtained with PMA $(=\mathrm{Cq}+\mathrm{PMA}): N_{0+\mathrm{PMA}}=N_{\mathrm{Cq}+\mathrm{PMA}} / 2^{(\mathrm{Cq}+\mathrm{PMA})}$. The initial number of total oocysts (i.e., viable and dead) was derived from the $\mathrm{Cq}$ values obtained without PMA $(=\mathrm{Cq}-$ PMA): $N_{0-\mathrm{PMA}}=N_{\mathrm{Cq}-\mathrm{PMA}} / 2^{(\mathrm{Cq}-\mathrm{PMA})}$. The percentage of viable oocysts in each suspension (untreated and heat-killed) was determined as follows: $N_{0+\mathrm{PMA}} / \mathrm{N}_{0-\mathrm{PMA}}=2^{\text {(Cq-PMA }-}$ 
$\mathrm{Cq}+\mathrm{PMA}) \times 100 . \mathrm{Cq}-\mathrm{PMA}-\mathrm{Cq}+\mathrm{PMA}(\Delta \mathrm{Cq})$ corresponded to the signal reduction and was calculated between each $\mathrm{Cq}$ value obtained with and without PMA (two independent DNA extractions and two PCR replicates per DNA extraction minimum). Viability percentage was established for each $\Delta \mathrm{Cq}$ and plotted as the mean, maximum, minimum, first and third quartiles, and median values. The signal reduction data $(\Delta \mathrm{Cq})$ were expressed as means with standard deviations.

\section{Determination of the viability percentage in oocyst suspensions using RT-qPCR assays}

The number of total oocysts $\left(N_{0 \text { tot }}\right)$ was determined using calibration curves that were established as follows. DNA was extracted from tenfold serial dilutions of known quantities of oocysts and amplified (see above). The $\log _{10}$ number of total oocysts per reaction was then plotted against $\mathrm{Cq}$ values obtained from each dilution. The number of viable oocysts $\left(N_{\text {0viable }}\right)$ was also derived from calibration curves that were established as follows: mRNA was extracted from tenfold serial dilutions of known quantities of oocysts and submitted to RT-qPCR (see above). The $\log _{10}$ number of viable oocysts per reaction was then plotted against $\mathrm{Cq}$ values obtained from each dilution. The viability percentage $N_{\text {0viable }} / N_{\text {0tot }} \times 100$ was calculated for each control suspension.

\section{Statistical analysis}

According to the Shapiro-Wilk test, the data sets followed a non-normal distribution $(p<0.05)$. The viability percentages and signal reduction values were compared using the nonparametric Kruskal-Wallis test. If the null hypothesis $\mathrm{H}_{0}$ ("the tested conditions have no effect on the measured value") was rejected, then post hoc Dunn tests were performed for pairwise multiple comparisons. All statistical tests were performed with the AnaStats plugin for Microsoft@ Excel 2010 (http://www. anastats.fr/outils.php). Statistical difference was considered as $p<0.05$.

\section{Results}

\section{Permeability of T. gondii oocysts to PMA}

Microscopic analyses revealed that sporozoites in untreated oocysts did not stain red following PMA incubation (Fig. 1a, panels 1-6) while the majority of heat-killed oocysts showed red staining within the sporocysts and sporozoites (Fig. 1a, panels 7-12). Release of sporocysts from heated oocysts was observed (asterisk, Fig. 1a, panel 12), reflecting the damages that were induced by heating to the oocyst wall. The proportion of sporulated oocysts that were permeable to PMA (PMA positive, PMA+) in untreated and heat-killed oocysts populations was then assessed by flow cytometry (Fig. 1b). Untreated and heat-killed oocyst suspensions contained $22.9 \%$ and $91.1 \%$ PMA+ oocysts, respectively (Fig. 1b, panels 3-4). These data demonstrated that PMA was able to penetrate within oocysts and sporozoites, and that heat-killed oocysts were more permeable to PMA than untreated oocysts in the tested conditions.

\section{Optimization of PMA treatment to detect viable oocysts by PMA-qPCR}

Untreated and heat-killed oocysts (sporulated and unsporulated) were incubated with different PMA concentrations $(50,100$, and $150 \mu \mathrm{M})$ and incubation temperatures $(22$, 37 , and $45^{\circ} \mathrm{C}$ ) and viable oocysts were detected by qPCR (Table 1). At $22{ }^{\circ} \mathrm{C}$, none of the tested PMA concentrations allow the abolition of the PCR signal in heat-killed oocysts, while heat-killed oocysts were not detected by RT-qPCR (Table 1). The mean viability percentage of untreated oocysts ranged between $27.2 \%$ and $48.9 \%$ and decreased as the PMA concentration increased ( $p<0.05$; Fig. 2$)$. The mean viability percentages were very similar in heat-killed oocysts $(24.9 \%$ to $41.2 \%$ ) ( $p>0.05$ when compared to untreated oocysts at each PMA concentration). This result could be due to the incomplete penetration of PMA in heat-killed oocysts still leading to a qPCR signal. In order to increase oocyst permeability to PMA, higher incubation temperatures $\left(37\right.$ and $\left.45^{\circ} \mathrm{C}\right)$ were tested. As observed at $22{ }^{\circ} \mathrm{C}$, PCR amplification was not abolished in heat-killed oocysts following incubation with $100 \mu \mathrm{M}$ PMA (Table 1). The viability percentage of heated oocysts was lower at $45{ }^{\circ} \mathrm{C}$ compared to $37{ }^{\circ} \mathrm{C}$ (respectively $22.0 \%$ and $45.6 \% ; p<0.05$; Fig. 3 ), suggesting that the penetration of PMA was favored at $45^{\circ} \mathrm{C}$. However, the viability of untreated oocysts was also significantly affected at $45{ }^{\circ} \mathrm{C}$ (26.2\% at $45^{\circ} \mathrm{C}$ vs. $54.1 \%$ at $37^{\circ} \mathrm{C} ; p<0.05$; Fig. 3 ). Overall, untreated and heated oocysts showed the same levels of viability, irrespective of the incubation temperatures with PMA ( $p>0.05$; Fig. 3 and Online Resource 1). The mean viability of untreated and/or heat-killed oocysts also tended to decrease as the PMA concentration increased at both temperatures, as observed at $22^{\circ} \mathrm{C}(p<0.05$; Online Resources 1 and 2$)$. Based on these results, oocysts were incubated with $100 \mu \mathrm{M}$ PMA for $30 \mathrm{~min}$ at $22^{\circ} \mathrm{C}$ in the following experiments.

\section{Effect of the amplicon length on PMA-qPCR signal reduction in heat-killed oocysts}

Two new primers were designed to increase the length of the amplicon of the 529-bp repeat element (RE) target, while keeping the TaqMan probe and respecting the conditions suitable for qPCR analyses (see "Materials and methods" section). The two PCR assays were applied on untreated and heat-killed oocysts incubated with $100 \mu \mathrm{M}$ PMA for $30 \mathrm{~min}$ 
(a)

Autofluorescence
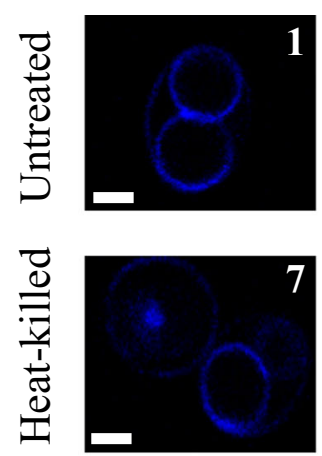
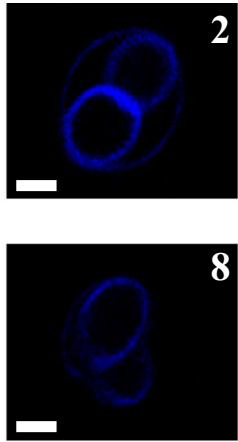

PMA
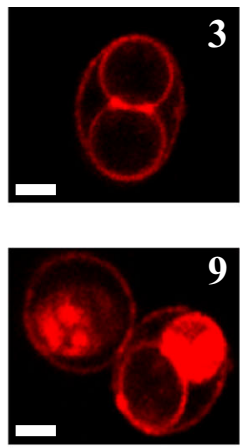
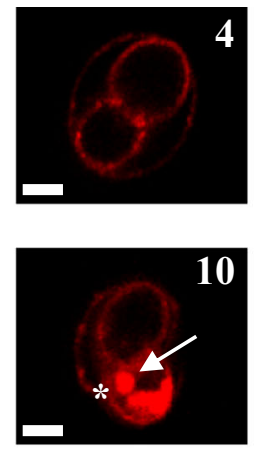

Merge
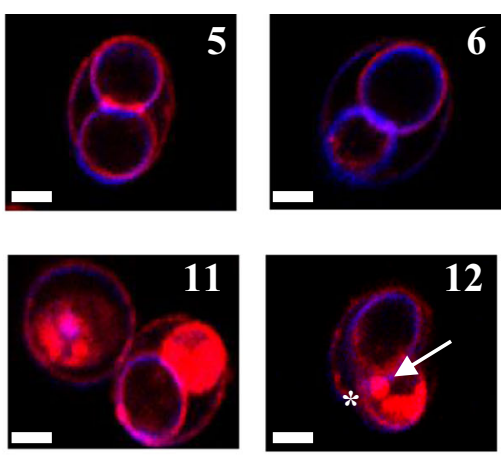

12

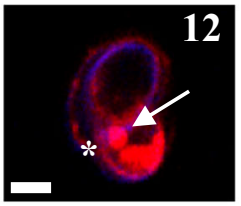

(b)

Untreated oocysts

(1)

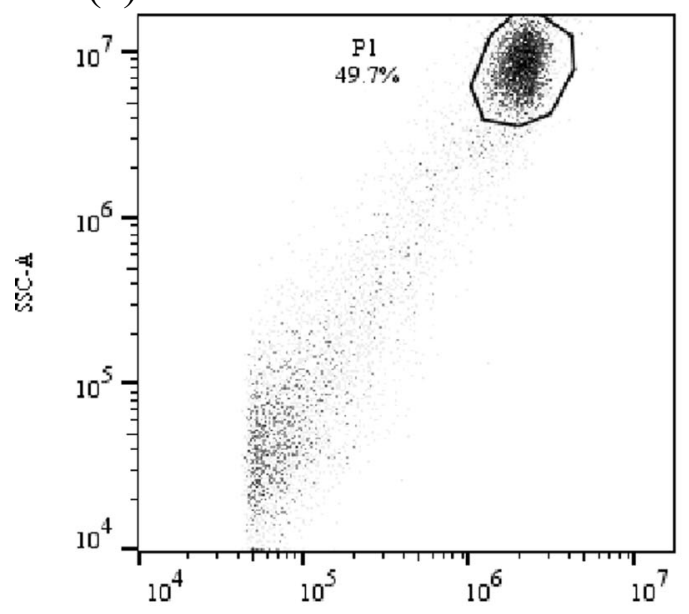

(3)

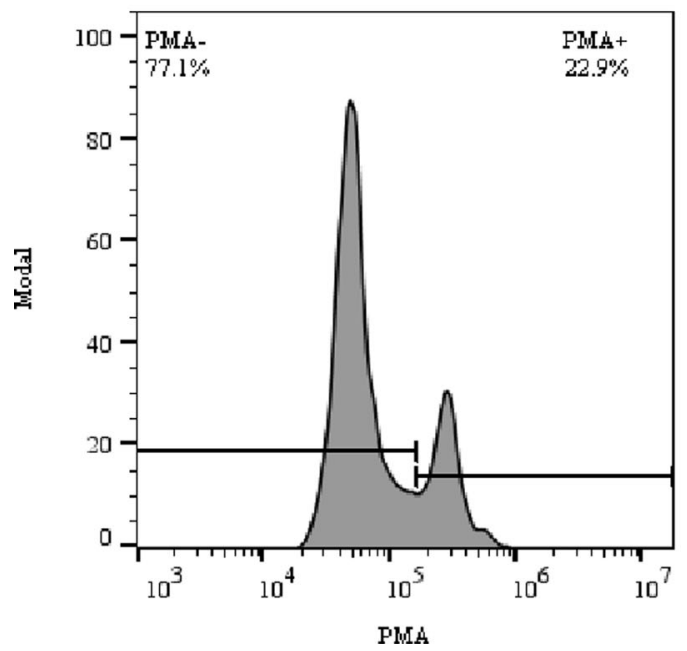

Heat-killed oocysts

(2)

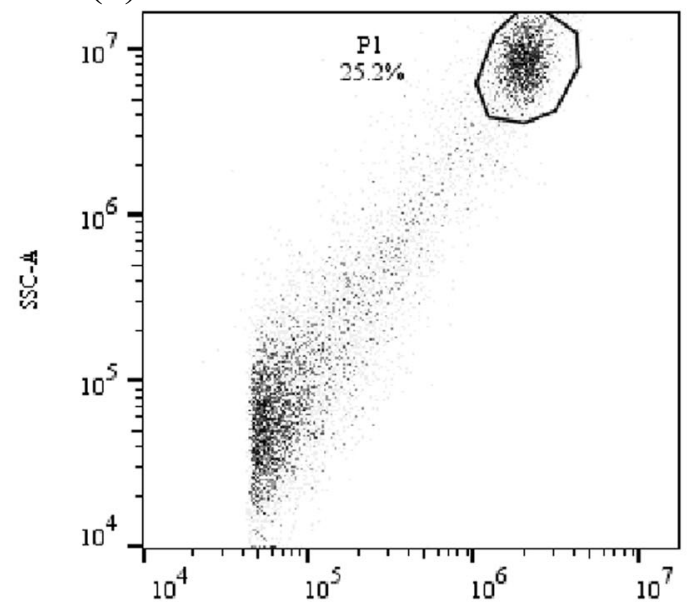

(4)

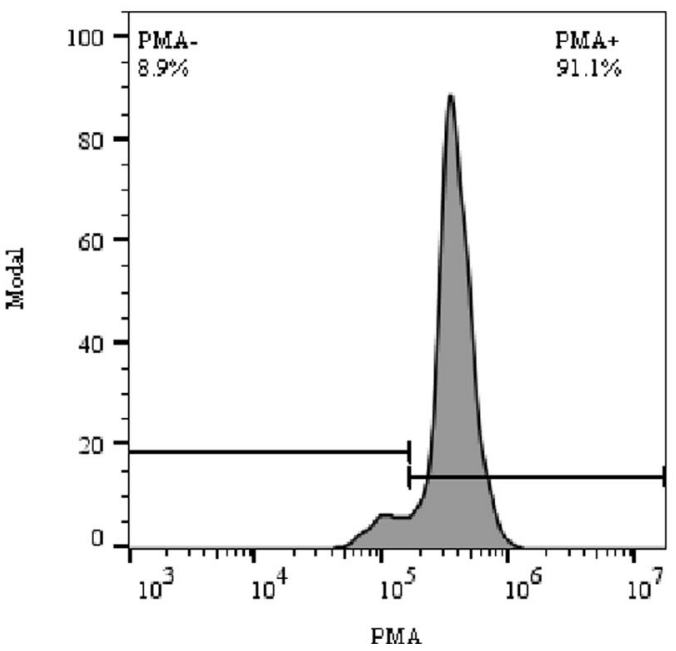


Fig. 1 Permeability of T. gondii oocysts to PMA assessed by (a) confocal microscopy and (b) flow cytometry. (a) Panels 1-6, untreated oocysts; panels $7-12$, heat-killed oocysts $\left(99{ }^{\circ} \mathrm{C}\right.$, $5 \mathrm{~min})$. Oocysts were observed for their blue autofluorescence (1-2, 7-8), PMA staining (3-4, 9-10), and corresponding merge $(5-6,11-12)$. Arrow shows a sporozoite inside a sporocyst and asterisk shows the partial release of a sporocyst from the oocyst. Bar $=5 \mu \mathrm{m}$. (b) Panels 1-3, untreated oocysts; panels 2-4, heatkilled oocysts. Size (FSC-A) and granularity (SSC-A) dot plots of oocysts (1-2); the gate (P1) was defined to include all blue autofluorescent elements with size and granularity of oocysts (sporulated and unsporulated). Percentage of sporulated oocysts that have incorporated PMA (PMA+) or not (PMA-) (3-4). The $x$-axis represents the PMA fluorescence intensity. The $y$-axis indicates the percentage of oocysts (number of oocysts at each fluorescence intensity relative to the total number of oocysts in each population, i.e., PMA+ or PMA-)

at $22{ }^{\circ} \mathrm{C}$. None of them led to a complete PCR signal extinction in heat-killed oocysts (Table 2). The longer amplicons of the RE target (123 and $283 \mathrm{bp}$ ) produced larger reductions in the PCR signal $(\triangle \mathrm{Cq})$ compared to the reference $81 \mathrm{bp}$ amplicon in heat-killed oocysts $(p<0.05$; Table 2 and Online Resource 3). However, for the 283-bp amplicon, a significant increased $\Delta \mathrm{Cq}$ was also observed in the untreated oocysts compared to the other amplicons $(p<0.05$; Table 2, Online Resource 3), preventing to measure viability reduction $\left(0.003 \log _{10}\right.$; Table 2$)$ and to discriminate viable from dead oocysts $(p>0.05$; Online Resource 3$)$. At the opposite, the 123-bp amplicon led to significant differences between untreated and heat-killed oocysts $(p<0.05$; Online Resource 3 ). Although discriminative, this assay was able to measure only $0.5 \log _{10}$ reduction of oocyst viability following heating (Table 2).

Table 1 Cq values obtained by PMA-qPCR in different incubation conditions (temperature and PMA concentrations) and by RT-qPCR, in untreated and heat-killed $\left(99^{\circ} \mathrm{C}, 5 \mathrm{~min}\right)$ oocysts

\begin{tabular}{|c|c|c|c|c|}
\hline & $\begin{array}{l}\text { Incubation } \\
\text { temperature } \\
\left({ }^{\circ} \mathrm{C}\right)\end{array}$ & $\begin{array}{l}\text { PMA } \\
\text { concentration } \\
(\mu \mathrm{M})\end{array}$ & $\begin{array}{l}\mathrm{Cq}^{\mathrm{a}} \\
\text { Untreated }\end{array}$ & $\begin{array}{l}\mathrm{Cq}^{\mathrm{a}} \\
\text { Heat-killed }\end{array}$ \\
\hline \multirow[t]{8}{*}{ PMA-qPCR } & $22^{\circ} \mathrm{C}$ & 0 & $20.65 \pm 0.17$ & $22.38 \pm 0.21$ \\
\hline & & 50 & $21.70 \pm 0.10$ & $23.69 \pm 0.19$ \\
\hline & & 100 & $22.23 \pm 0.34$ & $24.40 \pm 0.26$ \\
\hline & & 150 & $22.55 \pm 0.19$ & $24.48 \pm 0.47$ \\
\hline & $37^{\circ} \mathrm{C}$ & 0 & $23.26 \pm 0.38$ & $22.88 \pm 0.28$ \\
\hline & & 100 & $24.19 \pm 0.05$ & $24.04 \pm 0.12$ \\
\hline & $45^{\circ} \mathrm{C}$ & 0 & $22.73 \pm 0.01$ & $25.12 \pm 1.13$ \\
\hline & & 100 & $25.09 \pm 0.33$ & $27.40 \pm 0.53$ \\
\hline RT-qPCR & & & $29.36 \pm 0.76$ & ND \\
\hline
\end{tabular}

${ }^{a}$ Results are mean values of two independent experiments, each in duplicates. Standard deviations are indicated

$N D$ not detected
Effect of the number of targeted copy on PMA-qPCR signal reduction in heat-killed oocysts

The use of the multicopy target 529-bp RE might not favor PCR signal suppression due to copies not modified by PMA. The single-copy gene (SporoSAG) was therefore evaluated to increase the probability that PMA bound the targeted sequence. A PCR signal could still be detected in heat-killed oocysts using the SporoSAG target (Table 2). Signal reduction in heat-killed oocysts was slightly enhanced using the single copy target $(-2.27$, Table 2$)$ compared to the multicopy $81-$ bp RE reference amplicon $(-1.51 ; p<0.05$; Table 2 and Online Resource 3 ) but remained significantly lower relative to the RE 123-bp amplicon $(-3.36 ; p<0.05$; Table 2 and Online Resource 3). Moreover, the SporoSAG target did not lead to significant difference between untreated and heat-killed oocysts $\left(-0.15 \log _{10}\right.$ viability reduction; $p>0.05$; Table 2 and Online Resource 3).

\section{Impact of $\mathrm{PMAxx}^{\mathrm{TM}}$ on the discrimination between viable and dead oocysts}

As observed with PMA, the signal reduction of PMAxx ${ }^{\mathrm{TM}}$ qPCR targeting the 123-bp RE sequence was significantly higher in heated oocysts compared to untreated oocysts ( $p<0.05$, Fig. 4). However, unlike PMA, PMAxx ${ }^{\mathrm{TM}}$ caused a significant reduction of the PCR signal also in untreated oocysts $(p<0.05$; Fig. 4$)$. These results suggested that $\mathrm{PMAxx}^{\mathrm{TM}}$ would be less specific to heat-killed oocysts and/ or that control oocysts would be more permeable to PMAxx ${ }^{\mathrm{TM}}$ than to PMA. Similar results were obtained for other REamplicon length and SporoSAG gene (Online Resource 4). Hence, in the tested conditions, PMAxx ${ }^{\mathrm{TM}}$ did not improve the discrimination between viable and dead oocysts compared to PMA.

\section{Discussion}

Information on the viability of $T$. gondii oocysts is crucial to establish the public health significance of the environmental transmission of the parasite. To date, only approaches based on infectivity of the parasites in laboratory animals and in vitro cell culture infection assays provide reliable information on oocyst viability and infectivity (Rousseau et al. 2018). However, these methods are not suitable for the assessment of exposure in humans, mainly due to their long time-to-results and ethical concerns for animal testing. In this regard, PMAbased PCR techniques appear promising in terms of implementation, cost, sensitivity, and rapid results (Zeng et al. 2016). In this purpose, our study addressed for the first time the potential of PMA-qPCR assay to discriminate viable versus dead T. gondii oocysts. 


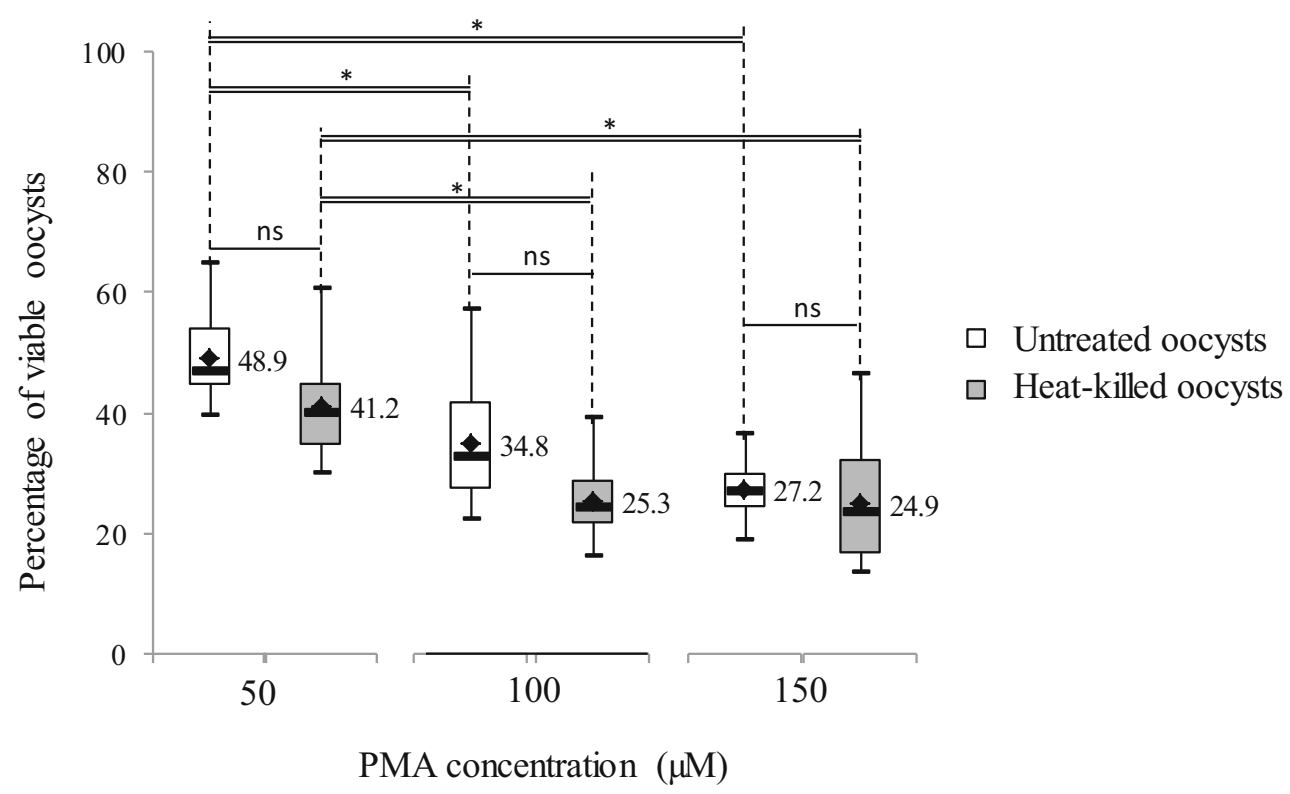

Fig. 2 Effect of PMA concentrations on the quantification of viable T. gondii oocysts in untreated and heat-killed suspensions. Untreated (white box) and heat-killed $\left(99^{\circ} \mathrm{C}, 5 \mathrm{~min}\right.$; gray box) oocysts (sporulated and unsporulated) were submitted to different PMA concentrations (50 to $150 \mu \mathrm{M}$ ) for $30 \mathrm{~min}$ in dark at $22{ }^{\circ} \mathrm{C}$. Percentages of viable oocysts for each concentration were determined relative to oocysts without PMA.
Each box represents the interquartile range and the horizontal line represents the median viability percentage $(n=2$ independent experiments in duplicates). The whiskers end at the largest and smallest viability percentages. Mean values (diamonds) are indicated. Asterisks and double traits show significant differences $(p<0.05)$; " $n s$ " and single trait indicate no significant difference $(p>0.05)$

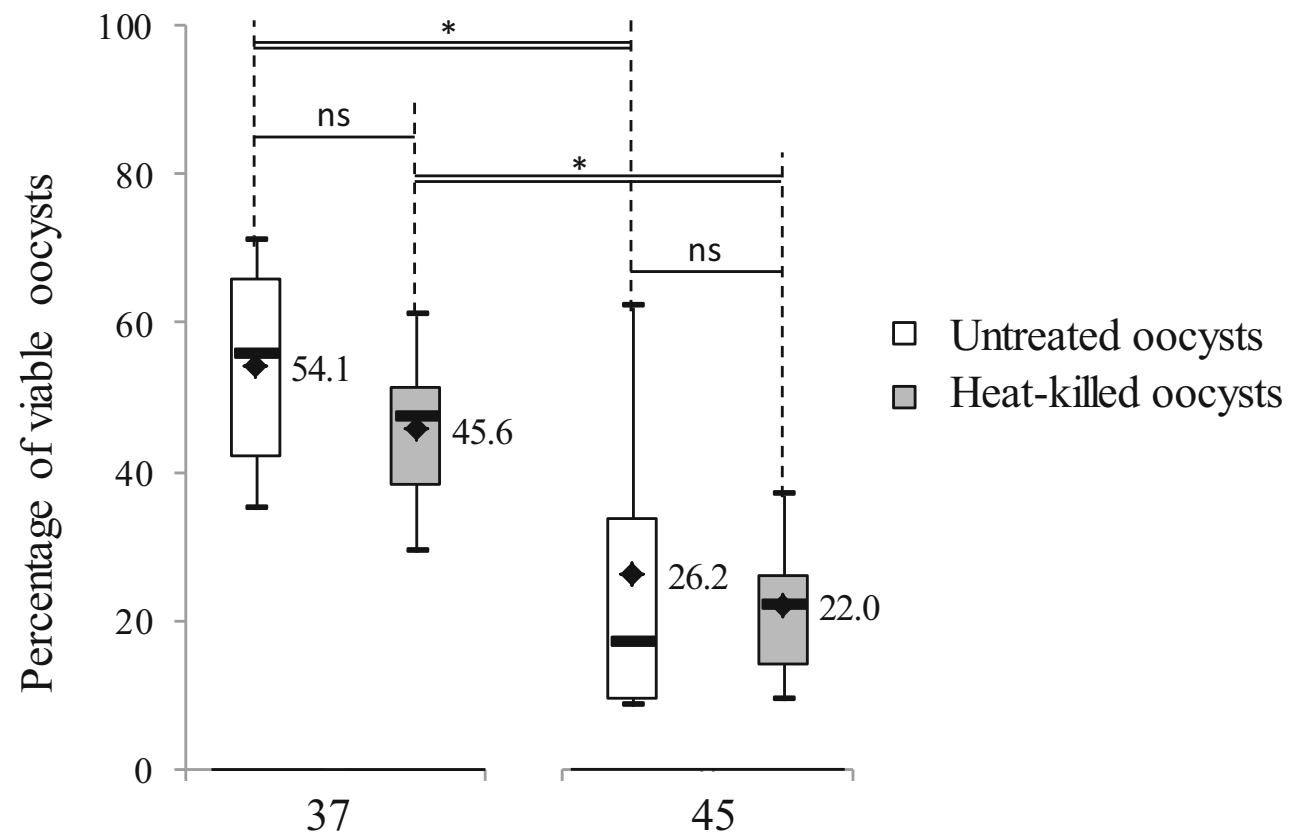

\section{PMA incubation temperatures $\left({ }^{\circ} \mathrm{C}\right)$}

Fig. 3 Effect of PMA incubation temperatures on the quantification of viable $T$. gondii oocysts in untreated and heat-killed suspensions. Untreated (white box) and heat-killed $\left(99^{\circ} \mathrm{C}, 5 \mathrm{~min}\right.$; gray box) oocysts (sporulated and unsporulated) were submitted to $100 \mu \mathrm{M}$ PMA for $30 \mathrm{~min}$ in dark at 37 or $45^{\circ} \mathrm{C}$. Percentages of viable oocysts for each concentration were determined relative to oocysts without PMA. Each box represents the interquartile range and the horizontal line the median viability percentage ( $n=2$ independent experiments in duplicates). The whiskers end at the largest and smallest viability percentages. Mean values (diamonds) are indicated. Asterisks and double traits show significant differences $(p<0.05)$; "ns" and single trait indicate no significant difference $(p>0.05)$ 
Table 2 Effect of amplicon length and of selected target gene on PMA-qPCR signal reduction $(\Delta \mathrm{Cq})$ in untreated and heat-killed $\left(99{ }^{\circ} \mathrm{C}, 5\right.$ min) oocysts

\begin{tabular}{|c|c|c|c|c|c|}
\hline & & \multicolumn{3}{|c|}{$\begin{array}{l}\text { Multicopy } \\
\text { 529-bp RE sequence }\end{array}$} & \multirow{2}{*}{$\begin{array}{l}\text { Monocopy } \\
\text { SporoSAG gene } \\
71 \mathrm{bp}\end{array}$} \\
\hline & & $81 \mathrm{bp}$ & $123 \mathrm{bp}$ & $283 \mathrm{bp}$ & \\
\hline \multirow[t]{2}{*}{$\Delta \mathrm{Cq}^{\mathrm{a}}$} & Untreated & $-1.90 \pm 0.62$ & $-1.69 \pm 0.66$ & $-2.62 \pm 0.95$ & $-1.78 \pm 1.06$ \\
\hline & Heat-killed & $-1.51 \pm 0.37$ & $-3.36 \pm 0.85$ & $-2.63 \pm 1.05$ & $-2.27 \pm 0.55$ \\
\hline \multicolumn{2}{|c|}{$\log _{10}$ viability reduction ${ }^{\mathrm{b}}$} & 0.12 & -0.5 & 0.003 & -0.15 \\
\hline
\end{tabular}

${ }^{\mathrm{a}} \Delta \mathrm{Cq}=\mathrm{Cq}-\mathrm{PMA}-\mathrm{Cq}+\mathrm{PMA}(100 \mu \mathrm{M}$, room temperature); mean values and standard deviations of three independent experiments, each in duplicates, are indicated

${ }^{\mathrm{b}}$ Viability reduction $=2^{\Delta \Delta \mathrm{Cq}} ; \Delta \Delta \mathrm{Cq}=\Delta \mathrm{Cq}$ heat-killed $-\Delta \mathrm{Cq}$ untreated

Oocysts of $T$. gondii are considered to be almost impermeable to water-soluble molecules due to the molecular organization of the bilayered oocyst and sporocyst walls that surround the sporozoites (Ferguson et al. 1975; Speer et al. 1998; Dumètre et al. 2013). Consistent with this, most of the untreated oocysts excluded PMA while oocysts heated at $99^{\circ} \mathrm{C}$ for $5 \mathrm{~min}$ were more permeable to PMA as assessed by confocal microscopy and flow cytometry. This suggests that such heating conditions could alter the integrity of the oocyst and sporocyst walls and sporozoite membrane thus favoring PMA inclusion into DNA. The effect of heating on the oocyst wall structure remains poorly documented in $T$. gondii. In contrast to our observations, Dumètre et al. (2013) reported that heating oocysts at $80^{\circ} \mathrm{C}$ for 10 min can reduce infiltration of an IgM monoclonal antibody specific to the inner layer of the oocysts wall, suggesting that, in these experimental conditions, heating did not affect microscopically the integrity of the oocyst walls. However, these results cannot be directly compared with our data as oocyst suspensions differed in age ( $<3$ m.o. vs. 8 m.o.) and storage conditions $\left(\mathrm{dH}_{2} \mathrm{O}\right.$ vs. sulfuric acid solution), and PMA is a much smaller molecule (440 Da) than IgM $(970 \mathrm{kDa})$. Heating oocysts at $99^{\circ} \mathrm{C}$ for $5 \mathrm{~min}$ could also induce more severe damages to oocysts than at $80{ }^{\circ} \mathrm{C}$ for $10 \mathrm{~min}$, leading to PMA inclusion. Preliminary experiments showed that freeze/thaw cycling and heating allowed the incorporation of PMA into sporozoites while sonication treatment did not (data not shown). These results suggest that PMA staining could give information on the overall permeability of the
Fig. 4 Comparison of PMA and PMAxx ${ }^{\mathrm{TM}} \mathrm{qPCR}$ assays in untreated and heat-killed $T$. gondii oocysts. Untreated (white bar) and heat-killed $\left(99^{\circ} \mathrm{C}, 5 \mathrm{~min}\right.$; gray bar) oocysts (sporulated and unsporulated) were submitted to $100 \mu \mathrm{M}$ of PMA or PMAxx ${ }^{\mathrm{TM}}$ for $30 \mathrm{~min}$ in dark at $22^{\circ} \mathrm{C}$. The 123 bp RE sequence was amplified by qPCR. Signal reduction values were obtained by subtracting the $\mathrm{Cq}$ values of dye-treated oocysts from oocysts without dye. Means and standard deviations of three independent experiments in duplicates are indicated. Asterisks show significant differences $(p<0.05)$

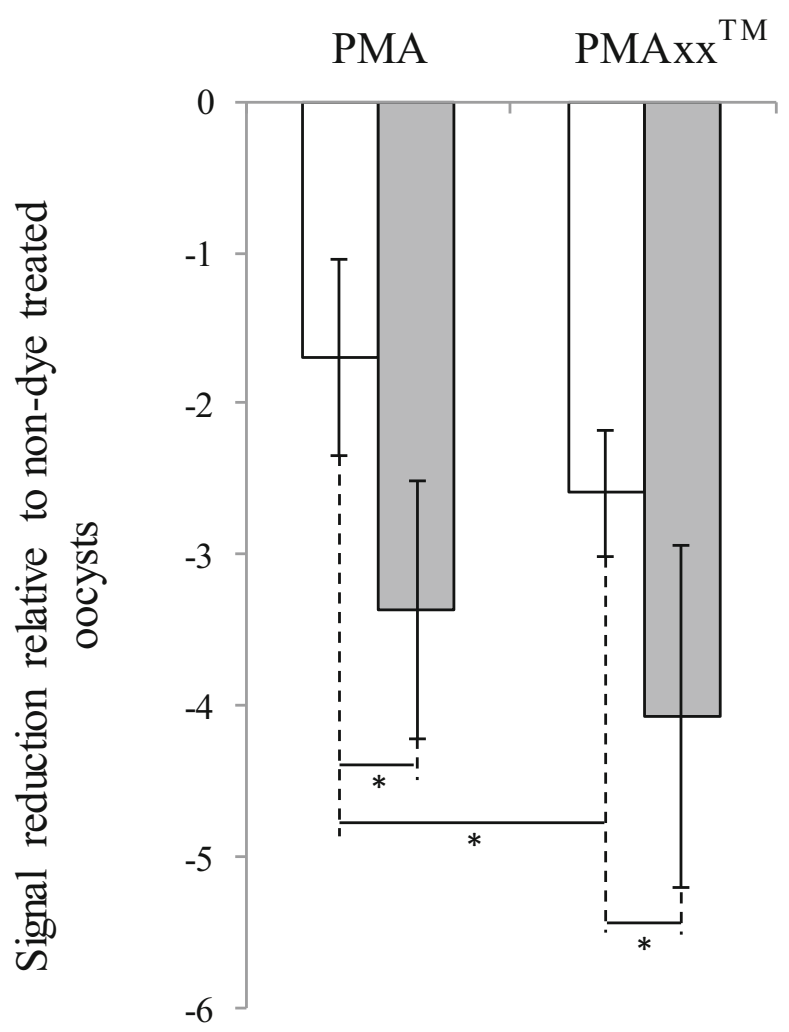

Untreated oocysts Heat-killed oocysts 
sporocyst and oocyst walls and be helpful to screen disinfecting agents acting on the oocyst wall structure and permeability. On the other hand, considering that some untreated viable oocysts can incorporate PMA, this dye would probably be not appropriate to assess the killing effect of molecules.

PMA treatment was then coupled with qPCR assays for viable/dead oocyst discrimination. The untreated oocyst suspensions showed between $27.2 \%$ and $48.9 \%$ of viable oocysts depending on PMA concentration. These percentages appeared to be lower than those determined by RT-qPCR assays (70\%). However, viability percentages determined by these different methods could not be compared, as the recovery rates and stability of extracted DNA and mRNA could be different. The low level of viability measured in the untreated oocyst suspension by PMA-qPCR may reflect the existence of membrane-compromised oocysts as already described for bacteria (Fittipaldi et al. 2012). In our study, oocysts were purified from cat feces by sucrose flotation. This process could lead to the purification of wall compromised and even dead oocysts as reported for sucrose-purified Cryptosporidium parvum oocysts (Kar et al. 2011). Flow cytometry analyses support these findings showing $22.9 \%$ of PMA-positive oocysts in the untreated suspension.

The proportion of viable oocysts in untreated suspension decreased as PMA concentration increased up to $150 \mu \mathrm{M}$. These results could be due to a cytotoxic effect of PMA in viable oocysts as described for bacteria such as Listeria monocytogenes and Legionella pneumophila (Fittipaldi et al. 2012). Such cytotoxicity was not observed in C. parvum oocysts submitted to $150 \mu \mathrm{M}$ PMA (Brescia et al. 2009). However, in their study, oocyst viability was determined by measuring the band intensity of PCR products on agarose gel which is a less sensitive method than qPCR performed in our study.

In the heat-killed oocyst suspension, PCR signal was still detected and the percentage of viability was not significantly different from the untreated oocysts. One can hypothesize that some oocysts still remained viable in the heated suspension. Based on mouse bioassays, $T$. gondii oocysts are no longer infective following heating above $60{ }^{\circ} \mathrm{C}$ (Ito et al. 1975; Travaillé et al. 2016; Ware et al. 2010). However, using RTqPCR assays, it has been shown that non-infective oocysts may still be viable (Travaillé et al. 2016). In this study, inactivation following heating $5 \mathrm{~min}$ at $99{ }^{\circ} \mathrm{C}$ has been assessed by RTqPCR and no signal was measured by RT-qPCR in heated oocysts indicating that no viable oocysts were present and that oocysts were efficiently killed, as already described (Travaillé et al. 2016). Such discrepancy between PMA-qPCR and RTqPCR assays was already reported in C. parvum oocysts following exposure to ammonia (Liang and Keeley 2012). Altogether, our data indicate that oocysts were fully inactivated by heating for $5 \mathrm{~min}$ at $99{ }^{\circ} \mathrm{C}$ but that PMA-qPCR assay did not allow the observation of such inactivation.
Flow cytometry analyses revealed that $8.9 \%$ of heat-killed T. gondii oocysts remained impermeable to PMA. This result can suggest that heating does not lead to efficient oocyst wall permeabilization and PMA penetration, producing similar viability percentages in the control and heated oocyst suspensions. To improve PMA inclusion, oocysts were incubated with PMA at 37 and $45{ }^{\circ} \mathrm{C}$ with the aim of increasing wall permeability as described for the wall of bacteria and spores (Rawsthorne et al. 2009; Nkuipou-Kenfack et al. 2013). A lower viability percentage was indeed measured in heatkilled oocysts following PMA incubation at $45^{\circ} \mathrm{C}$, suggesting that PMA penetration was favored at this temperature. However, the viability percentage was also lowered in untreated oocysts, while no effect on viability was measured by RTqPCR analyses (data not shown). This suggests that untreated oocysts were likely more permeable to PMA at $45{ }^{\circ} \mathrm{C}$. Alternatively, the PMA pre-incubation step might impact on the efficacy of DNA extraction and/or DNA integrity, rather than on the oocysts' viability. Taken together, none of the preincubation conditions we tested allow an optimal discrimination of viable and heat-killed oocysts.

The length of the nucleic acid target has been shown to play a crucial role in the suppression of PMA-PCR signal (Contreras et al. 2011). qPCR signal was abolished for heated G. duodenalis cysts with a 605-bp but not 77-bp amplicon of the tpi gene (Alonso et al. 2014)). In the same way, AgulloBarcello and collaborators (2014) also described a larger signal reduction using PMA-qPCR assays targeting a 834-bp versus 108-bp sequence of the $18 \mathrm{~S}$ gene of $C$. parvum oocysts. In our study, new primers were designed to increase the amplicon length of the 529-bp RE target from 81 to $283 \mathrm{bp}$, while remaining suitable for TaqMan qPCR assays (Rodríguez-Lázaro and Hernández 2013). The 123-bp amplicon showed the larger signal reduction in heat-killed oocysts and allowed viable/dead oocyst discrimination contrarily to other amplicon lengths. However, as reported in C. parvum (Alonso et al. 2014), an increase in amplicon length was correlated with the decrease of PCR efficacy ( $85 \%$ for the 283-bp amplicon compared to $92 \%$ for the reference).

The 529-bp RE has been shown to be repeated 200 to 300 times in the genome of $T$. gondii. RE-based qPCR assays have been correlated with higher sensitivity for parasite detection in clinical (Homan et al. 2000; Edvinsson et al. 2006), food (Hohweyer et al. 2016), and water (Yang et al. 2009) samples. However, as suggested by Contreras and collaborators (2011), a high number of copies could limit the efficacy of the PMA assay because PMA could not bind covalently to some copies. To overcome this drawback, the single-copy SporoSAG was tested using already published TaqMan qPCR system (Travaillé et al. 2016); however, it failed to completely abolish PCR signal in heat-killed oocyst suspension and no significant difference could be measured between untreated and heated oocysts using this PCR target. 
The new dye PMAxx ${ }^{\mathrm{TM}}$ is considered to be more effective than PMA at eliminating DNA amplification from dead cells. Moreover, it has been shown to be the best photoactivatable dye to detect signal reduction in thermally inactivated enteric viruses (Randazzo et al. 2016, 2018). Our results showed that, irrespective of the amplicon length and nucleic acid target, PMAxx ${ }^{\mathrm{TM}}$ PCR signals were still detected in heat-killed oocyst suspensions. With the exception of the SporoSAG gene, the PCR signal reductions measured in heated oocysts incubated with PMA and PMAxx ${ }^{\mathrm{TM}}$ were not significantly different. It should be noted that PMAxx ${ }^{\mathrm{TM}}$ was applied in distilled water that could limit its performances. Indeed, recent studies showed that the efficacy of PMAxx ${ }^{\mathrm{TM}}$ assay was improved by using PBS or Biotium Enhancer buffers instead of water (Randazzo et al. 2016, 2018). Like PMA, $\mathrm{PMAxx}^{\mathrm{TM}}$ provided discrimination between untreated and heat-killed oocysts only with the 123-bp RE amplicon. However, PMA-qPCR assay showed the highest level of viability reduction $\left(0.5 \log _{10}\right)$ following heating of oocysts. This level remains however very low compared to the 3-4 $\log _{10}$ viability reduction levels which are typically required for treatments intended to kill microorganisms (Nkuipou-Kenfack et al. 2013). Altogether, our results suggest that, in the tested conditions, PMA-qPCR underestimates the efficacy of heating in killing $T$. gondii oocysts.

The efficacy of PMA-based assay can be directly linked to the applied inactivation treatments and their effects on the cell integrity and membrane permeabilization that can correlate or not with the loss of viability (Cangelosi and Meschke 2014). Consistent with this, PMA-qPCR assays were able to show a decline in the viability of C. parvum oocysts exposed to hydrogen peroxide but not to ammonia, or following long-term storage (Liang and Keeley 2012). Preliminary results for T. gondii oocysts exposed to detergents showed a larger PMA-qPCR signal reduction than following heating treatment while still being infective (data not shown). Hence, the efficacy of PMA-qPCR assays for T. gondii oocysts submitted to other inactivation treatments have to be evaluated.

In conclusion, in the conditions tested in this study, PMAqPCR is able to assess the reduction of $T$. gondii oocyst viability following heating. However, PCR signals can still be detected in heat-killed oocysts leading to an underestimation of the inactivation efficacy of heating. In this regard, further works are required to evaluate the potential of this technique following other inactivation treatments than heating and the relevance of PMA-qPCR assays to characterize inactivation efficacy of industrial processes. Considering that animal assays are not realistic for such assessments, the scientific community is challenged to develop a laboratory-accessible method for discriminating viable/infective from non-infective T. gondii oocysts.
Acknowledgements This work was supported by the UMT ACTIA PROTORISK and the Universities of Reims Champagne-Ardenne and Rouen Normandie, in the frame of a $\mathrm{PhD}$ with a CIFRE agreement. A.D. is supported by the Institut Hospitalo-Universitaire (IHU), the National Research Agency (grant 10-IAHU-03), the Région Provence Alpes Côte d'Azur, and European funding FEDER PRIMI. The authors thank MOBICYTE, URCACyt, and PICT platforms, University Reims Champagne-Ardenne. We thank Mrs. Sabourin-Gibbs, Rouen University Hospital, for checking spelling and grammar.

\section{Compliance with ethical standards}

Conflict of interest The authors declare that they have no conflict of interest.

Open Access This article is distributed under the terms of the Creative Commons Attribution 4.0 International License (http:// creativecommons.org/licenses/by/4.0/), which permits unrestricted use, distribution, and reproduction in any medium, provided you give appropriate credit to the original author(s) and the source, provide a link to the Creative Commons license, and indicate if changes were made.

Publisher's note Springer Nature remains neutral with regard to jurisdictional claims in published maps and institutional affiliations.

\section{References}

Agulló-Barceló M, Moss JA, Green J, Gillespie S, Codony F, Lucena F, Nocker A (2014) Quantification of relative proportions of intact cells in microbiological samples using the example of Cryptosporidium parvum oocysts. Lett Appl Microbiol 58:70-78

Al-Megrin WAI (2010) Intestinal parasites infection among immunocompromised patients in Riyadh, Saudi Arabia. Pak J Biol Sci PJBS 13: 390-394

Alonso JL, Amorós I, Guy RA (2014) Quantification of viable Giardia cysts and Cryptosporidium oocysts in wastewater using propidium monoazide quantitative real-time PCR. Parasitol Res 113:26712678

Baldursson S, Karanis P (2011) Waterborne transmission of protozoan parasites: review of worldwide outbreaks - an update 2004-2010. Water Res 45:6603-6614

Baril L, Ancelle T, Goulet V, Thulliez P, Tirard-Fleury V, Carme B (1999) Risk factors for Toxoplasma infection in pregnancy: a case-control study in France. Scand J Infect Dis 31:305-309

Brescia CC, Griffin SM, Ware MW, Varughese EA, Egorov AI, Villegas EN (2009) Cryptosporidium propidium monoazide-PCR, a molecular biology-based technique for genotyping of viable Cryptosporidium oocysts. Appl Environ Microbiol 75:6856-6863

Cancino-Faure B, Fisa R, Alcover MM et al (2016) Detection and quantification of viable and nonviable Trypanosoma cruzi parasites by a propidium monoazide real-time polymerase chain reaction assay. Am J Trop Med Hyg 94:1282-1289. https://doi.org/10.4269/ ajtmh.15-0693

Cangelosi GA, Meschke JS (2014) Dead or alive: molecular assessment of microbial viability. Appl Environ Microbiol 80:5884-5891. https://doi.org/10.1128/AEM.01763-14

Caradonna T, Marangi M, Del Chierico F et al (2017) Detection and prevalence of protozoan parasites in ready-to-eat packaged salads on sale in Italy. Food Microbiol 67:67-75. https://doi.org/10.1016/j. fm.2017.06.006

Cattani F, Barth VC, Nasário JSR et al (2016) Detection and quantification of viable Bacillus cereus group species in milk by propidium 
monoazide quantitative real-time PCR. J Dairy Sci 99:2617-2624. https://doi.org/10.3168/jds.2015-10019

Cong W, Zhang N-Z, Hou J-L, Wang XC, Ma JG, Zhu XQ, Chen GJ (2017) First detection and genetic characterization of Toxoplasma gondii in market-sold oysters in China. Infect Genet Evol J Mol Epidemiol Evol Genet Infect Dis 54:276-278. https://doi.org/10. 1016/j.meegid.2017.07.014

Contreras PJ, Urrutia H, Sossa K, Nocker A (2011) Effect of PCR amplicon length on suppressing signals from membranecompromised cells by propidium monoazide treatment. J Microbiol Methods 87:89-95. https://doi.org/10.1016/j.mimet. 2011.07.016

Dubey JP (2010) Toxoplasmosis of animals and humans, 2nd edn. CRC Press, Boca Raton, Florida

Dumètre A, Dubey JP, Ferguson DJP et al (2013) Mechanics of the Toxoplasma gondii oocyst wall. Proc Natl Acad Sci U S A 110: $11535-11540$

Edvinsson B, Lappalainen M, Evengård B, ESCMID Study Group for Toxoplasmosis (2006) Real-time PCR targeting a 529-bp repeat element for diagnosis of toxoplasmosis. Clin Microbiol Infect Off Publ Eur Soc Clin Microbiol Infect Dis 12:131-136

Elizaquível P, Aznar R, Sánchez G (2014) Recent developments in the use of viability dyes and quantitative PCR in the food microbiology field. J Appl Microbiol 116:1-13. https://doi.org/10.1111/jam.12365

Ferguson DJ, Hutchison WM, Siim JC (1975) The ultrastructural development of the macrogamete and formation of the oocyst wall of Toxoplasma gondii. Acta Pathol Microbiol Scand [B] 83:491-505

Fittipaldi M, Nocker A, Codony F (2012) Progress in understanding preferential detection of live cells using viability dyes in combination with DNA amplification. J Microbiol Methods 91:276-289. https://doi.org/10.1016/j.mimet.2012.08.007

Fongaro G, Hernández M, García-González MC, Barardi CRM, Rodríguez-Lázaro D (2016) Propidium monoazide coupled with PCR predicts infectivity of enteric viruses in swine manure and biofertilized soil. Food Environ Virol 8:79-85. https://doi.org/10. 1007/s12560-015-9225-1

Ghozzi K, Marangi M, Papini R, Lahmar I, Challouf R, Houas N, Ben Dhiab R, Normanno G, Babba H, Giangaspero A (2017) First report of Tunisian coastal water contamination by protozoan parasites using mollusk bivalves as biological indicators. Mar Pollut Bull 117:197-202. https://doi.org/10.1016/j.marpolbul.2017.01.057

Habtewold T, Groom Z, Duchateau L, Christophides GK (2015) Detection of viable plasmodium ookinetes in the midguts of Anopheles coluzzi using PMA-qrtPCR. Parasit Vectors 8:455. https://doi.org/10.1186/s13071-015-1087-8

Harito JB, Campbell AT, Tysnes KR, Dubey JP, Robertson LJ (2017) Lectin-magnetic separation (LMS) for isolation of Toxoplasma gondii oocysts from concentrated water samples prior to detection by microscopy or qPCR. Water Res 114:228-236. https://doi.org/ 10.1016/j.watres.2017.02.044

Hohweyer J, Cazeaux C, Travaillé E, Languet E, Dumètre A, Aubert D, Terryn C, Dubey JP, Azas N, Houssin M, Loïc F, Villena I, la Carbona S (2016) Simultaneous detection of the protozoan parasites Toxoplasma, Cryptosporidium and Giardia in food matrices and their persistence on basil leaves. Food Microbiol 57:36-44. https:// doi.org/10.1016/j.fm.2016.01.002

Homan WL, Vercammen M, De Braekeleer J, Verschueren H (2000) Identification of a 200- to 300-fold repetitive $529 \mathrm{bp}$ DNA fragment in Toxoplasma gondii, and its use for diagnostic and quantitative PCR. Int J Parasitol 30:69-75

Inoue $\mathrm{H}$, Takama T, Yoshizaki M, Agata K (2015) Detection of Legionella species in environmental water by the quantitative PCR method in combination with ethidium monoazide treatment. Biocontrol Sci 20:71-74. https://doi.org/10.4265/bio.20.71
Ito S, Tsunoda K, Taki T, Nishikawa H, Matsui T (1975) Destructive effect of heating against Toxoplasma oocysts. Natl Inst Anim Health Q (Tokyo) 15:128-130

Kapperud G, Jenum PA, Stray-Pedersen B, Melby KK, Eskild A, Eng J (1996) Risk factors for Toxoplasma gondii infection in pregnancy. Results of a prospective case-control study in Norway. Am J Epidemiol 144:405-412

Kar S, Gawlowska S, Daugschies A, Bangoura B (2011) Quantitative comparison of different purification and detection methods for Cryptosporidium parvum oocysts. Vet Parasitol 177:366-370. https://doi.org/10.1016/j.vetpar.2010.12.005

Karanis P, Aldeyarbi HM, Mirhashemi ME, Khalil KM (2012) The impact of the waterborne transmission of Toxoplasma gondii and analysis efforts for water detection: an overview and update. Environ Sci Pollut Res Int 20(1):86-99

Lalle M, Possenti A, Dubey JP, Pozio E (2018) Loop-mediated isothermal amplification-lateral-flow dipstick (LAMP-LFD) to detect Toxoplasma gondii oocyst in ready-to-eat salad. Food Microbiol 70:137-142. https://doi.org/10.1016/j.fm.2017.10.001

Lee E-S, Lee M-H, Kim B-S (2015) Evaluation of propidium monoazidequantitative PCR to detect viable Mycobacterium fortuitum after chlorine, ozone, and ultraviolet disinfection. Int J Food Microbiol 210:143-148. https://doi.org/10.1016/j.ijfoodmicro.2015.06.019

Liang Z, Keeley A (2012) Comparison of propidium monoazidequantitative PCR and reverse transcription quantitative PCR for viability detection of fresh Cryptosporidium oocysts following disinfection and after long-term storage in water samples. Water Res 46: 5941-5953

Ma J, Feng Y, Hu Y, Villegas EN, Xiao L (2016) Human infective potential of Cryptosporidium spp., Giardia duodenalis and Enterocytozoon bieneusi in urban wastewater treatment plant effluents. J Water Health 14:411-423. https://doi.org/10.2166/wh. 2016.192

Marchioro AA, Tiyo BT, Colli CM, de Souza CZ, Garcia JL, Gomes ML, Falavigna-Guilherme AL (2016) First detection of Toxoplasma gondii DNA in the fresh leafs of vegetables in South America. Vector Borne Zoonotic Dis Larchmt 16:624-626. https://doi.org/ 10.1089/vbz.2015.1937

Moreno Y, Moreno-Mesonero L, Amorós I, Pérez R, Morillo JA, Alonso JL (2018) Multiple identification of most important waterborne protozoa in surface water used for irrigation purposes by $18 \mathrm{~S}$ rRNA amplicon-based metagenomics. Int J Hyg Environ Health 221:102111. https://doi.org/10.1016/j.ijheh.2017.10.008

Nkuipou-Kenfack E, Engel H, Fakih S, Nocker A (2013) Improving efficiency of viability-PCR for selective detection of live cells. J Microbiol Methods 93:20-24. https://doi.org/10.1016/j.mimet. 2013.01.018

Palos Ladeiro M, Aubert D, Villena I, Geffard A, Bigot A (2014) Bioaccumulation of human waterborne protozoa by zebra mussel (Dreissena polymorpha): interest for water biomonitoring. Water Res 48:148-155

Randazzo W, López-Gálvez F, Allende A, Aznar R, Sánchez G (2016) Evaluation of viability PCR performance for assessing norovirus infectivity in fresh-cut vegetables and irrigation water. Int J Food Microbiol 229:1-6. https://doi.org/10.1016/j.ijfoodmicro.2016. 04.010

Randazzo W, Piqueras J, Rodríguez-Díaz J, Aznar R, Sánchez G (2018) Improving efficiency of viability-qPCR for selective detection of infectious HAV in food and water samples. J Appl Microbiol 124: 958-964. https://doi.org/10.1111/jam.13519

Rawsthorne H, Dock CN, Jaykus LA (2009) PCR-based method using propidium monoazide to distinguish viable from nonviable Bacillus subtilis spores. Appl Environ Microbiol 75:2936-2939. https://doi. org/10.1128/AEM.02524-08 
Robert-Gangneux F, Dardé M-L (2012) Epidemiology of and diagnostic strategies for toxoplasmosis. Clin Microbiol Rev 25:264-296. https://doi.org/10.1128/CMR.05013-11

Rodríguez-Lázaro D, Hernández M (2013) Introduction to the real-time polymerase chain reaction. In: Rodríguez-Lázaro D (ed) Real-time PCR in food science: current technology and application. Caister Academic Press, Norfolk, pp 3-19

Rousseau A, La Carbona S, Dumètre A et al (2018) Assessing viability and infectivity of foodborne and waterborne stages (cysts/oocysts) of Giardia duodenalis, Cryptosporidium spp., and Toxoplasma gondii: a review of methods. Parasite Paris Fr 25:14. https://doi. org/10.1051/parasite/2018009

Speer CA, Clark S, Dubey JP (1998) Ultrastructure of the oocysts, sporocysts, and sporozoites of Toxoplasma gondii. J Parasitol 84: $505-512$

Sung K, Hiett KL, Stern NJ (2005) Heat-treated Campylobacter spp. and mRNA stability as determined by reverse transcriptase-polymerase chain reaction. Foodborne Pathog Dis 2:130-137. https://doi.org/10. 1089/fpd.2005.2.130

Tei FF, Kowalyk S, Reid JA, Presta M, Yesudas R, Mayer DC (2016) Assessment and molecular characterization of human intestinal parasites in bivalves from Orchard Beach, NY, USA. Int J Environ Res Public Health 13:381. https://doi.org/10.3390/ijerph13040381

Travaillé E, La Carbona S, Aubert D et al (2016) Development of qRTPCR method to assess viability of Giardia intestinalis cysts, and Cryptosporidium spp. and Toxoplasma gondii oocysts. Food Control 59:359-365

Vande Burgt NH, Auer A, Zintl A (2018) Comparison of in vitro viability methods for Cryptosporidium oocysts. Exp Parasitol 187:30-36. https://doi.org/10.1016/j.exppara.2018.03.002

Vesper S, McKinstry C, Hartmann C, Neace M, Yoder S, Vesper A (2008) Quantifying fungal viability in air and water samples using quantitative PCR after treatment with propidium monoazide (PMA). J
Microbiol Methods 72:180-184. https://doi.org/10.1016/j.mimet. 2007.11.017

Villena I, Aubert D, Gomis P, Ferte H, Inglard JC, Denis-Bisiaux H, Dondon JM, Pisano E, Ortis N, Pinon JM (2004) Evaluation of a strategy for Toxoplasma gondii oocyst detection in water. Appl Environ Microbiol 70:4035-4039

Ware MW, Augustine SAJ, Erisman DO, See MJ, Wymer L, Hayes SL, Dubey JP, Villegas EN (2010) Determining UV inactivation of Toxoplasma gondii oocysts by using cell culture and a mouse bioassay. Appl Environ Microbiol 76:5140-5147

Wells B, Shaw H, Innocent G, Guido S, Hotchkiss E, Parigi M, Opsteegh M, Green J, Gillespie S, Innes EA, Katzer F (2015) Molecular detection of Toxoplasma gondii in water samples from Scotland and a comparison between the 529 bp real-time PCR and ITS1 nested PCR. Water Res 87:175-181. https://doi.org/10.1016/j.watres. 2015.09.015

Xiao L, Zhang L, Wang HH (2012) Critical issues in detecting viable Listeria monocytogenes cells by real-time reverse transcriptase PCR. J Food Prot 75:512-517. https://doi.org/10.4315/0362-028X. JFP-11-346

Yang W, Lindquist HDA, Cama V, Schaefer FW, Villegas E, Fayer R, Lewis EJ, Feng Y, Xiao L (2009) Detection of Toxoplasma gondii oocysts in water sample concentrates by real-time PCR. Appl Environ Microbiol 75:3477-3483

Yu S, Yan L, Wu X, Li F, Wang D, Xu H (2017) Multiplex PCR coupled with propidium monoazide for the detection of viable Cronobacter sakazakii, Bacillus cereus, and Salmonella spp. in milk and milk products. J Dairy Sci 100:7874-7882. https://doi.org/10.3168/jds. 2017-13110

Zeng D, Chen Z, Jiang Y, Xue F, Li B (2016) Advances and challenges in viability detection of foodborne pathogens. Front Microbiol 7:1833. https://doi.org/10.3389/fmicb.2016.01833 